\title{
GEOMORFOLOGÍA Y PETROGRAFÍA DE LA COLADA ÁNGELES Y DEL CONO MONTE DE LA CRUZ, VOLCÁN BARVA, COSTA RICA
}

\author{
GEOMORPHOLOGY AND PETROGRAPHY OF ÁNGELES LAVA FLOW AND \\ THE MONTE DE LA CRUZ CINDER CONE, BARVA VOLCANO, COSTA RICA
}

\author{
Vanessa Rojas ${ }^{1,4 *}$, Dione Barahona ${ }^{2,4}$ y Guillermo E. Alvarado ${ }^{3,4}$ \\ ${ }^{1}$ Escuela Centroamericana de Geología, Universidad de Costa Rica, \\ Apdo. 214-2060, Costa Rica \\ ${ }^{2}$ Centro Servicio Recursos Geotérmicos, Instituto Costarricense de \\ Electricidad, Apdo. 10032-1000, Costa Rica \\ ${ }^{3}$ Área de Amenazas y Auscultación Sísmica y Volcánica, Instituto \\ Costarricense de Electricidad, Apdo. 10032-1000, Costa Rica \\ ${ }^{4}$ Centro de Investigación en Ciencias Geológicas (UCR), \\ Apdo. 214-2060, Costa Rica \\ *Autora para contacto: vanroh@gmail.com
}

(Recibido: 11/11/2016; aceptado: 17/04/2017)

\begin{abstract}
Monte de la Cruz complex piroclastic cone is located on the southeast footslope of Barva Volcano. This cone produced the Ángeles lava flow $\left(7,3 \mathrm{~km}\right.$, área $\left.12,8 \mathrm{~km}^{2}\right)$. Through geomorphological, petrographical and field studies, two units were recognized: Lower and Upper Ángeles. Petrographically, the Lower Ángeles corresponds with a vesicular andesitic-basaltic lava, with a hypocristalline porphyritic to glomeroporphyritic texture, with phenocrystals of plagioclase, clinopyroxene, orthopiroxene, olivine and opaque crystals. On the other hand, the Upper Ángeles is a vesicular andesitic lava with hypocristalline, glomeroporphyritic to glomeroporphyritic seriate texture, with phenocrystals of plagioclase, clinopyroxene, orthopiroxene, olivine and opaque crystals. Morphologically kipukas and lévees were observed. Regionally the Monte de la Cruz cone along with other minor satellite cones are aligned $\mathrm{N} 19^{\circ} \mathrm{W}$ over $8,5 \mathrm{~km}$, yielding a possible origin associated with a volcano-tectonic fracture.

Keywords: Cinder cone, Monte de la Cruz, Barva volcano, andesites, Geomorphology.
\end{abstract}

RESUMEN: En la falda sureste del volcán Barva se encuentra el cono piroclástico compuesto Monte de la Cruz, a partir del cual fue emitida la colada de lava Ángeles $\left(7,3 \mathrm{~km}\right.$, área 12,8 $\left.\mathrm{km}^{2}\right)$. Por medio de estudios geomorfológicos, petrográficos y trabajo de campo se dividió en dos unidades, Ángeles Inferior y Superior. Petrográficamente, Ángeles

Rojas, V., Barahona, D. y Alvarado, G. E. (2017). Geomorfología y petrografía de la colada Ángeles y del cono Monte de la Cruz, volcán Barva, Costa Rica. Revista Geológica de América Central, 56, 17-35. Doi: 10.15517/rgac.v0i56.29240 
Inferior corresponde con una lava andesítico basáltica vesicular de textura hipocristalina porfirítica a levemente glomeroporfirítica, con fenocristales de plagioclasa, clinopiroxenos, ortopiroxenos, olivinos y opacos. Ángeles Superior, por su parte, es andesítica vesicular con textura hipocristalina, glomeroporfirítica a glomeroporfirítica seriada, con fenocristales de plagioclasa, clinopiroxenos, ortopiroxenos, olivinos y opacos. Morfológicamente, fueron observadas kipukas y lévees. Regionalmente, se observa que el cono Monte de la Cruz, junto con otros conos satélites menores, están alineados $\mathrm{N} 19^{\circ} \mathrm{W}$ a lo largo de $8,5 \mathrm{~km}$, evidenciando un origen asociado a una fractura volcano-tectónica.

Palabras clave: Cono piroclástico, Monte de la Cruz, volcán Barva, andesitas, Geomorfología

\section{INTRODUCCIÓN}

En la literatura vulcanológica costarricense, desde mediados del siglo pasado, se nombran recurrentemente tres coladas de lava relativamente recientes como ejemplos representativos de tres volcanes que se ubican en la cordillera Central (Dóndoli, 1965; Dóndoli y Chaves, 1968): la colada Ángeles (volcán Barva), la colada Cervantes (volcán Irazú) y la colada Aquiares (volcán Turrialba). Estas coladas de lava, poseen por particularidad, que en la actualidad presentan un gran desarrollo urbanístico, cultivos varios, ganadería, e incluso turismo. Además, se originaron a lo largo de un sistema fisural de conos secundarios o satélites, todos sobre el flanco sur de los volcanes citados.

Un trabajo reciente describió con detalle la colada Cervantes (Alvarado y Vega, 2013), por lo que el presente trabajo continúa con la descripción en detalle de la colada Ángeles, asociada al sistema fisural de conos parásitos del flanco sursureste del volcán Barva, específicamente proveniente de la actividad volcánica del cono cerro Redondo o Monte de la Cruz (Fig. 1).

\section{RESEÑA HISTÓRICA}

El cerro Redondo ha recibido diferentes nombres a los largo de la historia. Una de las primeras menciones la hace Schaufelberger (1931) al referirse a esta área como "las lagunas de Heredia"; luego es referido como Cerro Redondo de la Cruz por Williams (1952) y Monte de la Cruz por Bohnenberger (1968). Sobre este último nombre, Salguero (2007), menciona que forma parte de los cuatro monumentos religiosos que se construyeron en el Valle Central durante la década de 1930: Monumentos a Cristo Rey en Ochomogo y cerro Espíritu Santo en Naranjo y los monumentos a la Cruz en el cerro San Miguel de Alajuelita y el Monte de la Cruz en Heredia, en el que además, se construyó una pequeña capilla en 1933 donde se oficiaban misas.

Actualmente, el nombre oficial es cerro Redondo, sin embargo, es conocido popularmente como Monte de la Cruz y en la zona de los cráteres, se ubica un centro turístico muy visitado conocido como Paradero Turístico Monte de la Cruz.

\section{TRABAJOS PREVIOS}

Numerosos estudios se han referido a la colada de lava Ángeles. Una de las primeras menciones es la de Schaufelberger (1931), quien menciona que "en los alrededores de las lagunas más bajas [Cerro Redondo y alrededores], salen dos corrientes de lava, formando dos corrientes con rumbo sur", indicando además que una de ellas se extiende sobre los Ángeles hasta San Rafael, mientras la otra, ubicado al oeste, se extiende hasta Barva. Continúa sus descripciones afirmando que posiblemente se trata de una colada prehistórica debido a su poca meteorización, la más reciente del volcán Barva, añadiendo que existen gran cantidad de cavernas y lagunas en el camino desde San Rafael hasta Ángeles.

Williams (1952) la describe como una colada de composición basáltica, blocosa y escoriácea, emitida por el cerro Redondo (Fig. 2). En los alrededores de este cerro menciona depresiones por tubos de lava colapsados con presencia de estalactitas, los cuales, de acuerdo con el autor, du- 


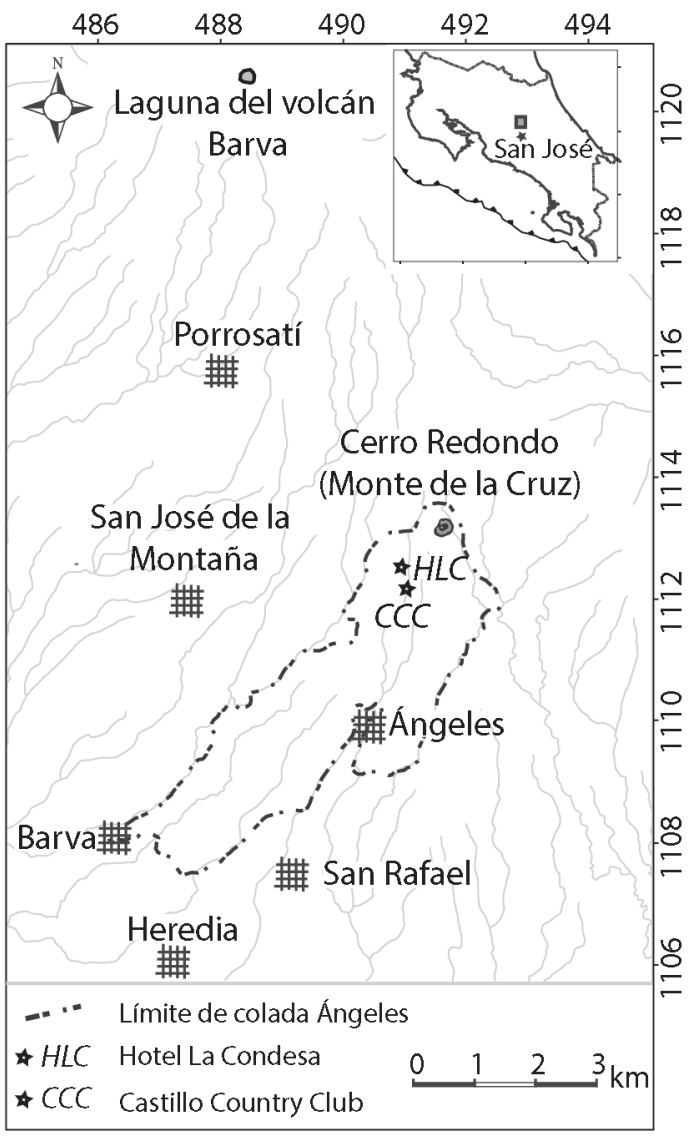

Fig. 1: Mapa de ubicación del área de estudio.

rante la época lluviosa se llenan de agua y han sido confundidos con lagunas cratéricas. Identifica cráteres miniatura, sin embargo, no especifica su ubicación o tamaño, únicamente expresa que son pocos.

Por medio de un estudio fotogeológico del oeste del Valle Central, Bohnenberger (1968), describe la colada Ángeles dentro de la unidad de lavas recientes, indicando que son una serie de coladas de lavas de composición variable (andesitas hasta basaltos), intercalados con lahares y paleosuelos. Aunado a esto, dibuja en su mapa el cono con tres cráteres. Estos cráteres también son mencionados por Saénz (1971), quién adicionalmente menciona que dos de ellos son abiertos y el otro posee una laguna.

Se muestra la representación de la colada en el Mapa Geológico del Valle Central (Dóndoli y Chaves, 1968), sin embargo, no se realiza ninguna descripción de la misma. Más tarde, Echandi (1981), también hace un mapa donde la representa, pero únicamente del sector sur de la colada y la menciona brevemente. Al igual que estos autores, otros más han delimitado la colada a lo largo del tiempo, con ciertas variaciones, incidiendo en sus dimensiones, tal y como se muestra en la figura $2 \mathrm{~A}$ y $2 \mathrm{~B}$.

Una descripción litológica y geomorfológica la realiza Protti (1986), el cual reporta lavas afaníticas y afanítico porfiríticas e indica la presencia de levées, tubos de lava y líneas de flujo. Además, estima un espesor de $15 \mathrm{~m}$ y un volumen eruptado entre 0,2 y $0,3 \mathrm{~km}^{3}$.

Gerardo Soto (comunicación escrita, 2014) propone una subdivisión en dos unidades, una denominada Los Ángeles Oeste y otra Los Ángeles Este, siendo la primera de ellas la inferior, caracterizada por ser menos porfirítica (menos de un $12 \%$ de fenocristales) que la unidad superior (al menos $30 \%$ de fenocristales).

Todos los autores coinciden en la juventud de esta colada, a juzgar por su marcada morfología y poca cobertura de ceniza, e indican que es la colada más joven emitida por el volcán Barva. Arredondo y Soto (2006), proponen una edad entre 10 y $15 \mathrm{ka}$.

\section{METODOLOGÍA}

Se realizó la integración de la información y la consulta de los estudios realizados dentro o en las cercanías del área de estudio. Se utilizaron las fotografías aéreas de 1967 a escala 1: 17000 y 1: 13 000, 1992 a escala 1: 60000 y TERRA 1997 a escala 1: 40000 para el estudio fotogeológico, complementado con el análisis del sector oriental de la Hoja Topográfica Barva (1: 50 000) del Instituto Geográfico Nacional (IGN) y otros mapas topográficos a diferentes escalas (1: 25000 y 1: 10000$)$, además de los modelos de elevación digital elaborados a través de Sistemas de Información Geográfica (SIG). También, se reinterpretó la información extraída de los pozos del Sistema Nacional de Aguas Subterráneas, Riego y Avenamiento (SENARA) para el control subterráneo.

El Museo Nacional aportó los datos de los hallazgos arqueológicos dentro y en los alrededores 


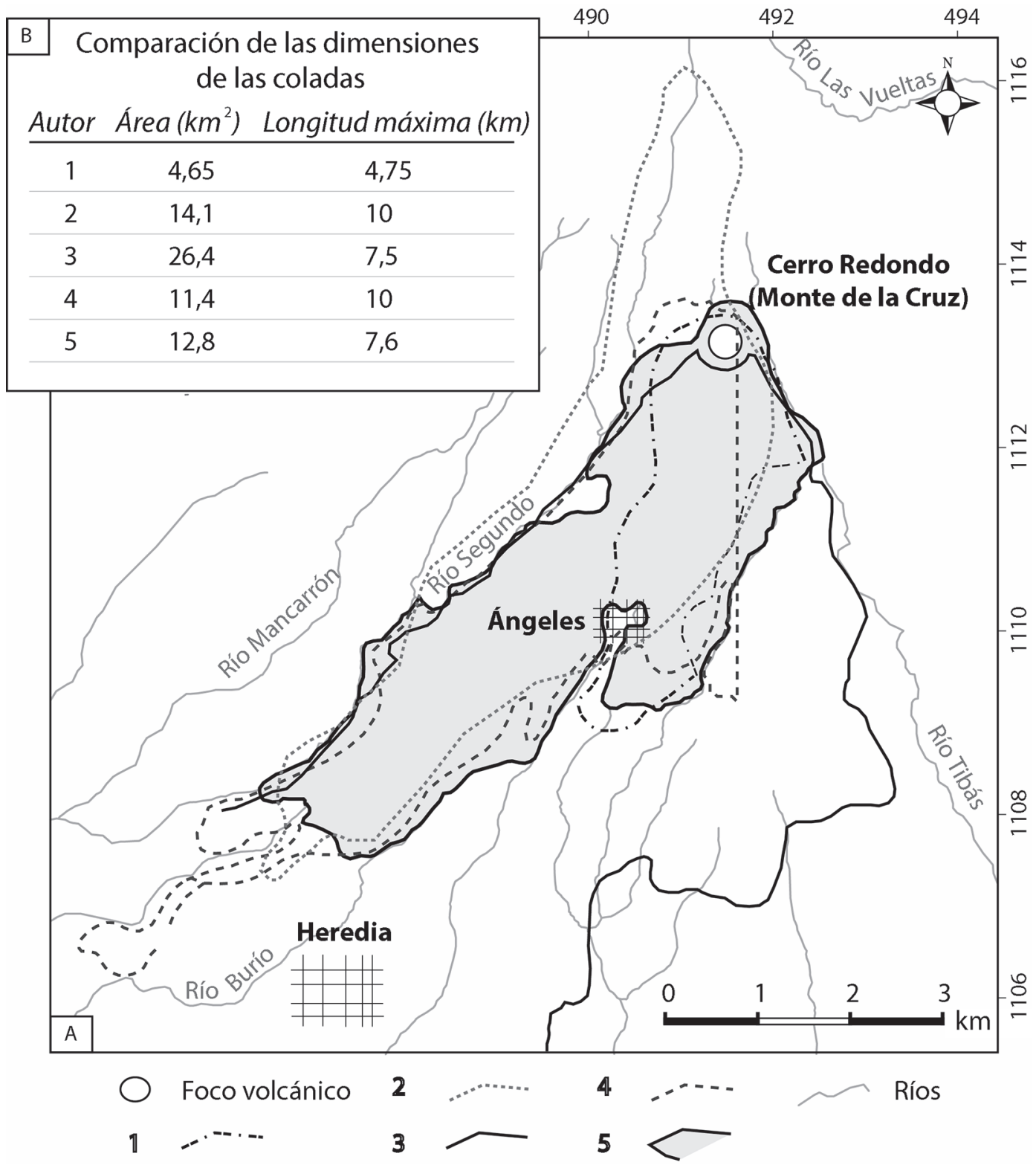

Fig. 2: A) Delimitaciones de la colada Ángeles a lo largo del tiempo según diferentes autores. 1: Williams (1952). 2: Dóndoli y Chaves (1968). 3: Bohnenberger (1968). 4: Protti (1986). 5: Presente trabajo, B) Cuadro comparativo con las dimensiones establecidas por diferentes autores para la colada Ángeles.

de la colada utilizados con el fin de establecer una edad relativa. Todo esto fue complementado con trabajo de campo en el cual se midieron espesores y se realizó una estimación de los volúmenes, dimensiones de la colada y otras geoformas asociadas. Así mismo, se seleccionaron 9 muestras de roca para la elaboración de secciones delgadas y su respectivo análisis petrográfico, las cuales permitieron definir las principales unidades de colada de lava y sus posibles flujos. 


\section{GEOMORFOLOGÍA DEL MONTE DE LA CRUZ Y LA COLADA ÁNGELES}

\section{Morfografía}

En la falda sur-sureste del volcán Barva se encuentra la colada de lava Ángeles, limitada al este por el río Turales y al oeste en su mayoría por el río Segundo (Fig. 3). Sobre ella sobresalen las poblaciones de Ángeles de San Rafael de Heredia (de ahí su nombre), Castillo, Getsemaní, Uvita, Palmar, Paso Viga, todas pertenecientes al cantón de San Rafael de Heredia y una parte del centro de Barva de Heredia. Además, de sitios de interés recreacional como el Centro Turístico Paradero Monte de la Cruz, el Castillo Country Club y hoteles-restaurantes, entre ellos La Condesa, hoy día cerrado (Fig. 1).

\section{Morfometría}

El cerro Redondo (1862 m s.n.m), es un cono piroclástico de base circular (Fig. 4A), con 325 $\mathrm{m}$ de diámetro basal y una altura desde la base de $45 \mathrm{~m}$. Sus pendientes son moderadas (entre $12^{\circ}$ y $20^{\circ} ; 17^{\circ}$ en promedio), siendo ligeramente más suaves hacia el norte $\left(14^{\circ}\right)$. Por medio de modelos del relieve se estimó un área de $0,11 \mathrm{~km}^{2} \mathrm{y}$ un volumen de $1,24 \times 10^{6} \mathrm{~m}^{3}$.

El cono posee al menos dos cráteres pequeños bien definidos, de $130 \mathrm{~m}$ y $90 \mathrm{~m}$ de diámetro, el primero de ellos en forma de herradura hacia el oeste, mientras el segundo presenta forma de anillo cerrado con un lago de $50 \mathrm{~m}$ de diámetro y que posee alrededor de $2 \mathrm{~m}$ de profundidad (Fig. 4B).

Hacia el sur del cono se observan dos depresiones semicirculares adicionales de pequeñas dimensiones (90 x $90 \mathrm{~m}$ ), que podrían corresponder con los cráteres descritos por Williams (1952), Bohnenberger (1968) y Saénz (1971), y posiblemente con las lagunas mencionadas por Schaufelberger (1931). Dichos cráteres tienen una morfología muy suavizada y poco evidente, probablemente por la cobertura de piroclastos del cono principal; actualmente no se visualizan dada la espesa cobertura boscosa. Por otro lado, a tan solo $150 \mathrm{~m}$ al norte del cerro Redondo se observa un cono pequeño de $85 \mathrm{~m}$ de diámetro basal, cuya altura desde la base se estima en $25 \mathrm{~m}$; su origen está posiblemente asociado con la misma actividad fisural del cerro Redondo.

Con base en la geomorfología y características petrográficas, se definieron dos unidades de colada de lava originadas por el cono piroclástico cerro Redondo. Una considerada como superior (localizada hacia el oriente), que se extiende desde el cerro Redondo hasta Ángeles y Palmar, mientras la inferior (localizada hacia el occidente) se observa a partir de estos poblados hasta el centro de Barva.

Con una longitud máxima de $6,5 \mathrm{~km}$ se extiende la unidad Ángeles Superior, cuya topografía cerca de la fuente es uniforme, caracterizada por pendientes bajas (entre $5^{\circ}$ y $8^{\circ}$ ), en contraste con el sector distal, en donde la topografía es más irregular con pendientes variables entre $\operatorname{los}\left(10^{\circ} \mathrm{y}\right.$ $17^{\circ}$ ). Termina en Palmar (al norte de San Rafael) $\mathrm{y}$ al norte de Paso Viga con un pequeño escarpe de entre 2 y $4 \mathrm{~m}$ de altura.

Al suroeste del cerro Redondo se observa una zona "hundida", cuyo origen podría corresponder con una pequeña área que no fue cubierta por la colada de lava, zonas denominadas kipukas. Algunas depresiones alargadas, posibles canales de escurrimiento limitados por levées, pueden ser observados en este sector norte, sin embargo, predominan en el sector sur de la Unidad Ángeles Superior. El más importante de ellos se observa al sur de Getsemaní, con rumbo norte a sur-suroeste, una longitud de $500 \mathrm{~m}$ y con un ancho de $100 \mathrm{~m}$. Varias unidades de flujo de la colada son observadas, todas ellas con direcciones de flujo hacia el suroeste (Fig. 3).

Al sureste del poblado de Ángeles, se observó un tubo de lava de $75 \mathrm{~cm}$ de ancho, $45 \mathrm{~cm}$ de alto y $1 \mathrm{~m}$ de profundidad, con presencia de estalactitas de lava milimétricas y centimétricas (Fig. 4C). Sin embargo, los tubos de lava mencionados por Schaufelberger (1931) y Protti (1986) no fueron observados, posiblemente debido a que las evidencias han sido cubiertas por las viviendas e infraestructura actual. Se consultó a los pobladores, pero dijeron no conocer otras cuevas o túneles en el área.

La unidad Ángeles Inferior se extiende 7,3 $\mathrm{km}$ desde la fuente de origen y posee un relieve irregular, sin embargo, predominan las pendientes 


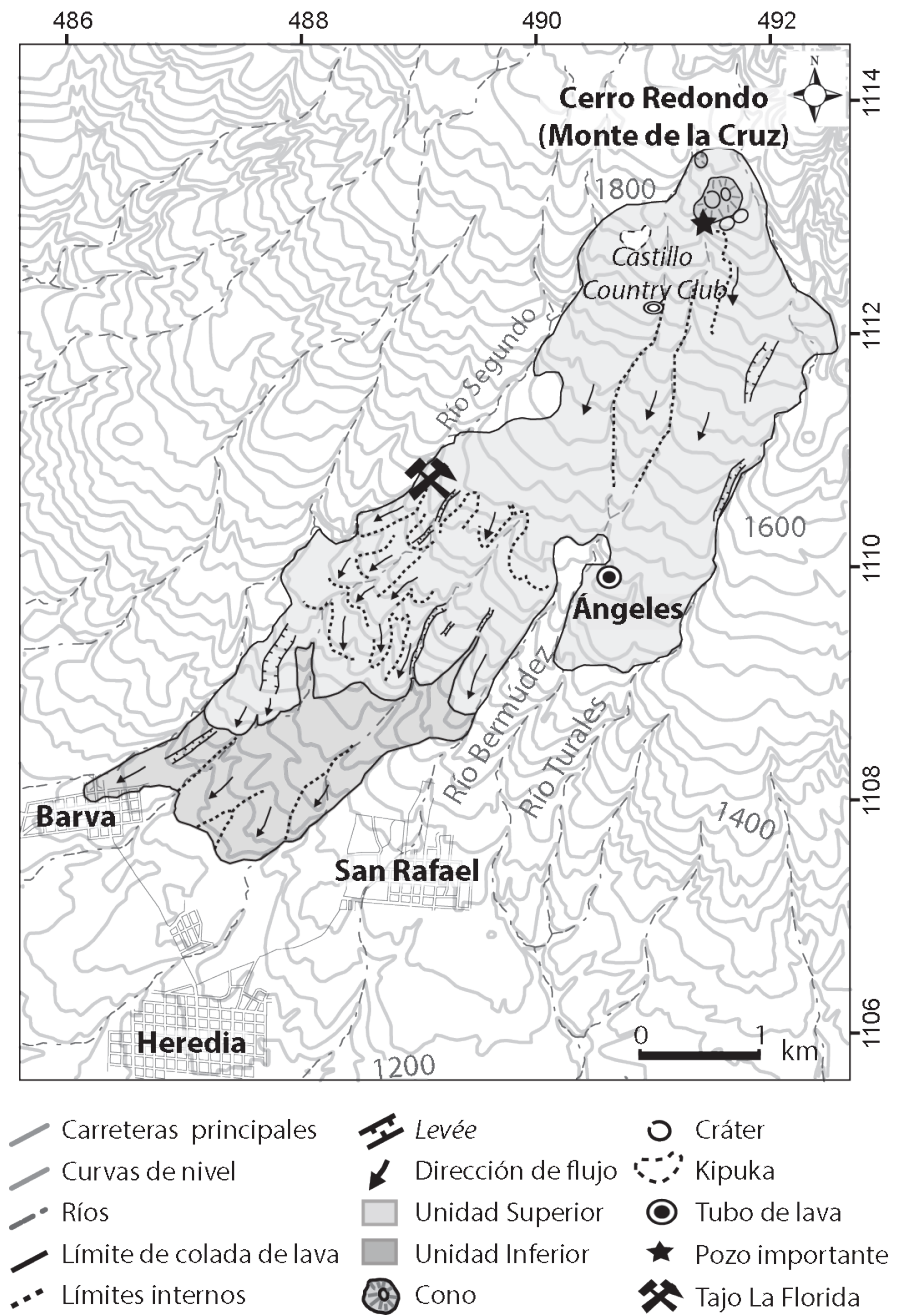

Fig. 3: Geomorfología de la colada Ángeles.

bajas, $5^{\circ}$ en promedio. Se observan varias unidades de flujo de la colada con dirección suroeste y en el sector oeste se observa un posible levée de unos $500 \mathrm{~m}$ de longitud y $70 \mathrm{~m}$ de ancho.

Los espesores máximos observados son entre 12 y $15 \mathrm{~m}$, encontrados en la catarata del río Turales, al oeste del cerro Redondo y en el tajo La Florida respectivamente. Además, se observa un espesor mínimo de 2,5 m en la gruta detrás de la iglesia católica de Barva (Fig. 5A), mientras en otros sectores, como en el cauce del río Bermúdez, en Ángeles, se observan $5 \mathrm{~m}$ y en el río Turales al suroeste de Ángeles, $8 \mathrm{~m}$.
Por otro lado, en los datos de las perforaciones de SENARA, se estima que el espesor promedio varía entre 30 y $35 \mathrm{~m}$ en la parte proximal, mientras en la parte distal ronda los $15 \mathrm{~m}$. A 150 $\mathrm{m}$ al sur de la cruz de cerro Redondo, se reportan 98 m de brechas lávicas en el pozo BA843, infiriéndose que este punto podría indicar la ubicación proximal del campo de lavas cercano al foco eruptivo.

Se calcula un volumen total para la colada Ángeles $\geq 0,33 \mathrm{~km}^{3}$, determinándose un aproximado de $0,15 \mathrm{~km}^{3}$ para la unidad Ángeles Superior y $0,18 \mathrm{~km}^{3}$ para la unidad Ángeles Inferior. 

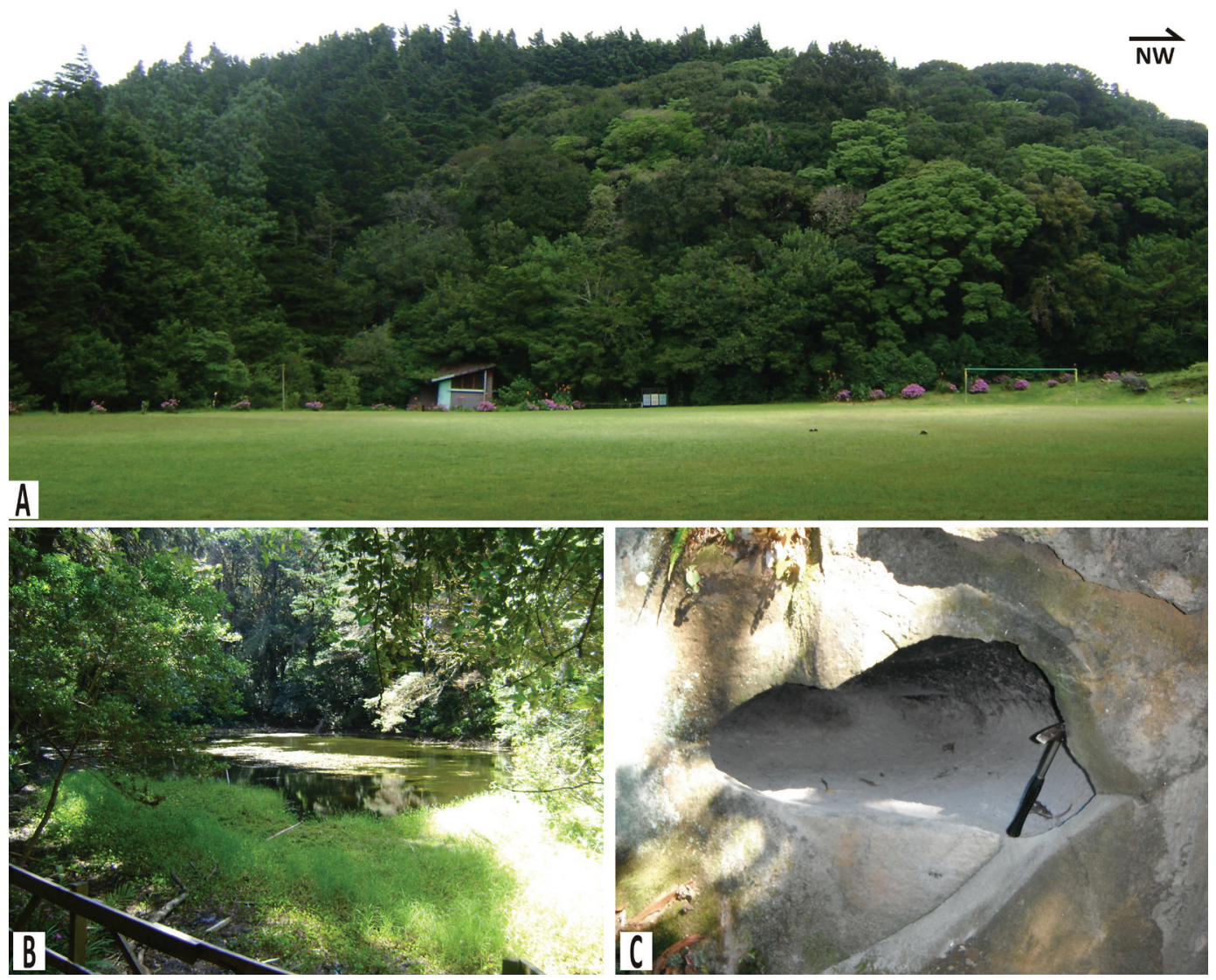

Fig. 4: A) Cono piroclástico cerro Redondo, B) Lago cratérico del cerro Redondo, C) Tubo de lava.

\section{ESTRUCTURA INTERNA Y PETROGRAFÍA}

Dentro de los principales afloramientos en que está expuesta la colada Ángeles se encuentran: la catarata del río Turales (491907 E / 1113043 N), en la margen izquierda del río Segundo (488262 E / 1110222 N) y especialmente el tajo La Florida en Getsemaní (489274 E / 1110576 N), en donde se pueden observar las dos unidades de coladas de lava (Figs. 5B y 6A) denominadas en este trabajo como: Ángeles Inferior y Ángeles Superior. De la unidad Ángeles Inferior (AI), se identifica en este tajo únicamente la parte superior con bloques escoriáceos decimétricos, de tipo andesítico basáltico vesicular, con un espesor máximo observado de 2,5 m (Fig. 6B), pátina de meteorización de tonalidad amarillenta y gris oscuro en superficie sana. Presenta desarrollo de un paleosuelo en la parte superior de esta zona brechosa $(15 \mathrm{~cm}$ de espesor máximo observado; Fig. 6C), de carácter discontinuo y que se encuentra ligeramente quemado por el arribo de la unidad Ángeles Superior (AS). En la gruta, detrás de la iglesia católica de Barva (Fig. 5A), sí es posible observar la parte más masiva de esta unidad.

La unidad Ángeles Superior corresponde con lavas de composición andesítica y está conformada por una secuencia de por lo menos dos coladas masivas (de 2 a $5 \mathrm{~m}$ de espesor cada una) alternadas entre sí por sus respectivas brechas de progresión (de 2 a $4 \mathrm{~m}$ de espesor) de aspecto blocoso, visiblemente más vesiculares y alteradas a óxidos de hierro (Fig. 7A). 

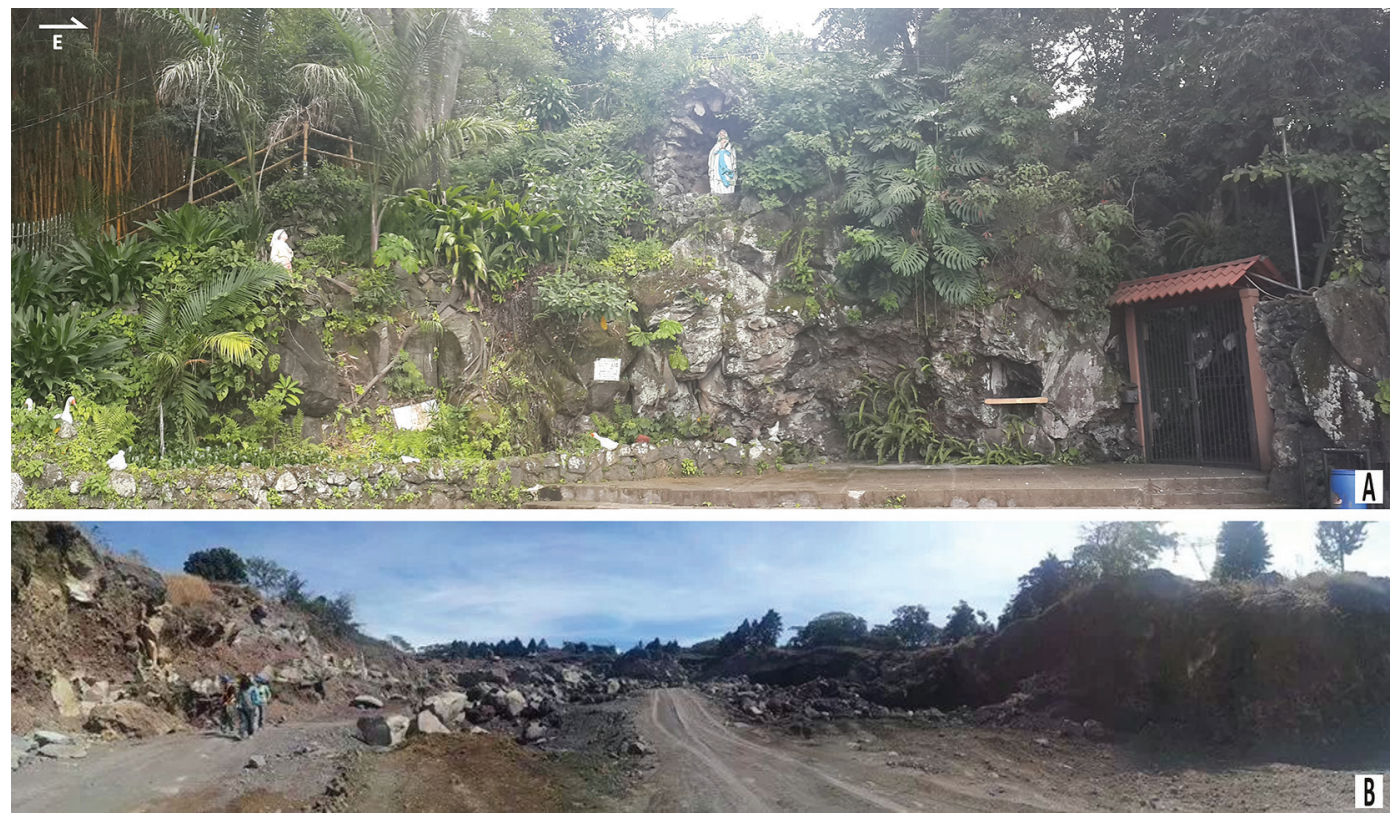

Fig. 5: A) Unidad Ángeles Inferior en la gruta, detrás de la iglesia católica de Barva (486420 E / 1108174), B) Vista general del tajo La Florida, en Getsemaní (489274 E / 1110576 N).

En las coladas masivas se aprecian fracturas de enfriamiento y rampas de flujo, que indican la dirección de movimiento de la colada (Fig. 7B), mientras en las brechas de progresión (autobrechas) se presentan bolas de lava (lava balls) con sectores acrecionados debido al avance de la colada (Fig. 7C).

\section{Petrografía}

Las siguientes son las características petrográficas que conforman la unidad Ángeles Inferior y la unidad Ángeles Superior, considerándose en la descripción las composiciones modales con vesículas. Adicionalmente, en el cuadro 1 se presenta un resumen con la composición modal con vesículas y también la composición normalizada sin vesículas.

El principal rasgo macroscópico que diferencia ambas unidades de la colada Ángeles, lo constituye el porcentaje de fenocristales: la unidad Ángeles Inferior (Fig. 8A) presenta entre 10 $15 \%$ de fenocristales, mientras la unidad Ángeles Superior (Fig. 8B) presenta una textura porfirítica más marcada o evidente con fenocristales comúnmente en un $25 \%$ y hasta un $35 \%$, identificándose fenocristales de plagioclasa y minerales máficos (entre ellos piroxenos).

\section{Unidad Ángeles Inferior}

Macroscópicamente, son lavas con textura afanítica porfirítica con fenocristales (aprox. 10 $15 \%$ del volumen total de la roca) de plagioclasas (de hasta $6 \times 2 \mathrm{~mm}$ ) y máficos (entre los cuales se identifican piroxenos) en una matriz gris oscuro de grano fino (aprox. $70-80 \%$ ) y con contenidos variables de vesículas desde poco menos de $10 \%$ hasta un $15 \%$. Microscópicamente, son lavas de tipo andesítico basáltico vesicular con una textura hipocristalina porfirítica a levemente glomeroporfirítica (Fig. 9C) con fenocristales (16-19\%), entre ellos: plagioclasa $(4,5-6 \%)$, clinopiroxenos $(5,5-7 \%)$, olivinos (3 - $5 \%)$, ortopiroxenos $(1-2$ $\%)$ y trazas de opacos en una matriz $(67-75 \%)$ intersertal-vesicular (Fig. 9A y 9B), compuesta por microlitos de plagioclasa con leve disposición subparalela, piroxenos, opacos, olivinos y vidrio 

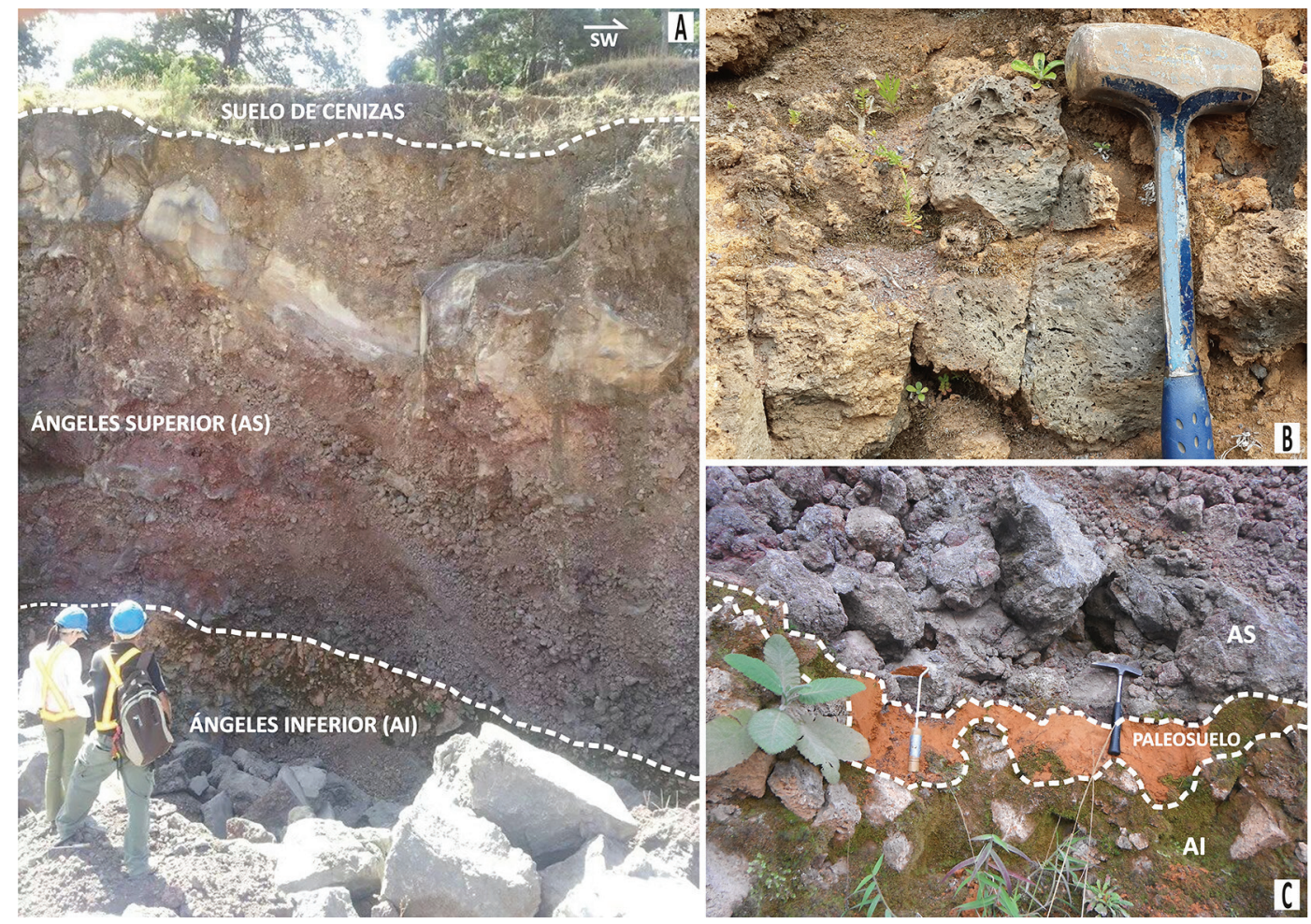

Fig. 6: Unidades de la colada Ángeles, tajo La Florida. A) Unidad Ángeles Inferior (AI) y unidad Ángeles Superior (AS), B) Detalle de bloques escoriáceos pertenecientes a la unidad Ángeles Inferior (parte brechosa superior), C) Paleosuelo que divide las unidades.

alterado a óxidos de hierro. Las vesículas constituyen entre 9 y $14 \%$ con un diámetro máximo de $0,4 \mathrm{~cm}$.

Las plagioclasas están fracturadas y con textura cribosa; presentan también bordes corroídos siendo menos común en los clinopiroxenos y ortopiroxenos. Los pocos megacristales de ortopiroxenos $(1-2 \%)$ presentan textura en corona de clinopiroxenos (Fig. 9D). Muchos de los olivinos son hipidiomórficos e idiomórficos, algunos con un leve borde de alteración a óxidos de hierro (iddingsitizados), presentes en un porcentaje importante como megafenocristales-fenocristales (3 - $5 \%$ ) y con presencia variable dentro de la matriz.

\section{Unidad Ángeles Superior}

En macroscopía, posee una textura afanítica porfirítica con fenocristales (aprox. 25 - $35 \%$ del volumen total de la roca) de plagioclasa (de hasta $6 \times 3 \mathrm{~mm}$ ) y piroxenos en una matriz gris oscuro de grano fino (aprox. 50 - $65 \%$ ) y comúnmente entre $10-15 \%$ de vesículas, pudiendo alcanzar hasta un $30 \%$ en el caso de la brecha de progresión o autobrecha, como se puede observar en el cerro Redondo y tajo La Florida. Sin embargo, en muestra del núcleo de la colada, observable en este tajo, se presentan sin vesículas. Microscópicamente, corresponden con lavas de composición andesítica vesicular con una textura hipocristalina, glomeroporfirítica a glomeroporfirítica seriada, con fenocristales (21 - $32 \%)$, entre ellos: plagioclasas (12 - 18\%), clinopiroxenos (5,5 - $8 \%$ ), ortopiroxenos $(1-4 \%)$, olivinos $(0,5-1$ $\%)$ y opacos $(1-1,5 \%)$ en una matriz (42 - 65 $\%$ ) intersertal-vesicular y menos común pilotaxítica, compuesta por microlitos de plagioclasa, que en algunos sectores presentan disposición subparalela; también se presentan piroxenos y vidrio café con variable alteración a óxidos de hierro, siendo esta alteración intensa en la brecha de progresión. 

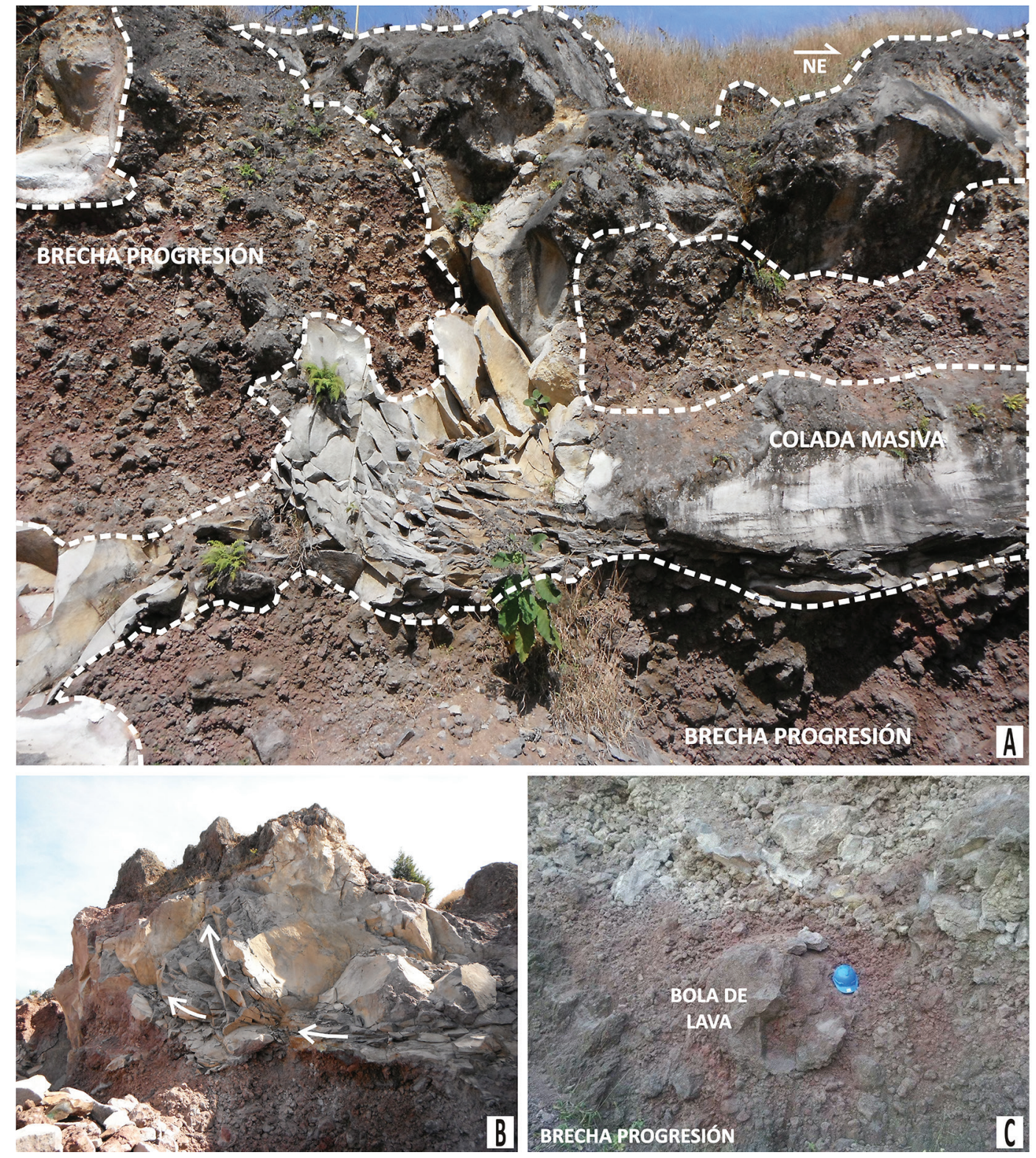

Fig. 7: Detalle de unidad Ángeles Superior, tajo La Florida. A) Coladas masivas y brechas de progresión, B) Fracturas de enfriamiento y rampas de flujo en colada masiva, C) Bola de lava (lava ball) en brecha de progresión.

Las vesículas varían entre 12 y $33 \%$ con diámetro máximo de $1,15 \mathrm{~cm}$. Se presenta cerca de un $3-3,5$ $\%$ de aglomeraciones importantes de cristales compuestas por plagioclasas, piroxenos, opacos y olivino; de 1 - 1,5\% parece corresponder con inclusiones y se encuentran principalmente en la brecha de progresión. En esta unidad, la presencia de olivino es esporádica especialmente en cantidades traza o máximo $1 \%$, tanto como fenocristales como dentro de alguna inclusión; únicamente alcanza cerca de $1,5 \%$ en alguna aglomeración importante de cristales.

Del análisis petrográfico, complementado con la geomorfología y el trabajo de campo, fue 
Cuadro 2

Composición petrográfica (modal con vesículas y normalizada sin vesículas) de las unidades que conforman la colada Ángeles.

\begin{tabular}{ccccc}
\hline Unidad & Ángeles Inferior & Ángeles Inferior & Ángeles Superior & Ángeles Superior \\
\hline Composición & $\begin{array}{c}\text { Rangos con } \\
\text { vesículas }\end{array}$ & $\begin{array}{c}\text { Rangos normalizados } \\
\text { sin vesículas }\end{array}$ & $\begin{array}{c}\text { Rangos con } \\
\text { vesículas }\end{array}$ & $\begin{array}{c}\text { Rangos normalizados } \\
\text { sin vesículas }\end{array}$ \\
\hline Fenocristales (\%) & $16-19$ & $18-22$ & $21-32$ & $24,4-41$ \\
Plagioclasa & $4,5-6$ & $5,2-7$ & $12-18$ & $14-22$ \\
Clinopiroxenos & $5,5-7$ & $6-8,1$ & $5,5-8$ & $6,5-14$ \\
Ortopiroxenos & $1-2$ & $1,1-2,3$ & $1-4$ & $1,2-6$ \\
Olivinos & $3-5$ & $3,3-6$ & $0,5-1$ & $0,6-1,2$ \\
Opacos & 0,5 & 0,6 & $1-1,5$ & $1-2,2$ \\
Aglomeraciones importantes de & & & $1-4,5$ & $1-5,3$ \\
cristales e inclusiones & $67-75$ & $78-82,4$ & $42-65$ & $59-75,6$ \\
Matriz (\%) & $9-14$ & & $12-33$ & 5 \\
Vesículas (\%) & & & \\
\hline
\end{tabular}

posible diferenciar dentro de esta unidad superior al menos dos flujos de lava alternados entre sí por sus respectivas brechas de progresión o autobrechas.

Particularmente, la brecha de progresión de estructura blocosa, se caracteriza por tener una matriz menos cristalizada y con fuerte alteración del vidrio a óxidos de hierro (Figs. 10A y 10B); así mismo muchos de los fenocristales se presentan con este tipo de alteración. Además, en esta brecha se presentan principalmente las inclusiones con textura holocristalina (Figs. 10C y 10D), compuestas por plagioclasa, piroxenos, opacos y en algunos pocos casos olivino iddingsitizado y trazas de biotita. Los ortopiroxenos se presentan muchos como megafenocristales y algunos con textura en corona (rodeados de clinopiroxenos), pero no es un rasgo preponderante. En la matriz, se nota en algunos sectores una leve disposición subparalela de los microlitos de plagioclasa, al igual que los fenocristales, que además tienen textura cribosa.

La colada masiva se caracteriza por tener una textura hipocristalina glomeroporfirítica seriada (Fig. 11A), con olivino, únicamente como fenocristal (en cantidades traza) o dentro de alguna inclusión (Fig. 11B). Los fenocristales de plagioclasas presentan en su mayoría textura cribosa y los ortopiroxenos textura en corona (rodeados de clinopiroxenos). En la matriz, los microlitos de plagioclasa tienen una leve disposición subparalela y en pocos casos pilotaxítica.

Con base en un análisis químico del Monte de la Cruz, McBirney y Williams (1965) describen una andesita con augita, hipersteno y olivino. Kussmaul, Gaínsa y Paniagua (1982) clasifican la misma muestra como una andesita basáltica o como una latiandesita cuarcífera, según el sistema de clasificación utilizado. Los siguientes minerales normativos son aportados por ellos: cuarzo $(7,85 \%)$, albita $(25,98 \%)$, anortita $(27,94 \%)$, ortosa $(7,10 \%)$, magnetita $(6,16 \%)$, ilmenita $(3,81 \%)$, apatito $(0,69 \%)$, hipersteno $(13,21 \%)$ y diópsido (7,20\%). El índice de color es de 31,12 \%, el índice máfico de $67,07 \%$ y la plagioclasa normativa de $51,82 \%$. Esta lava se ubica dentro de los rangos geoquímicos normales para otras lavas del volcán Barva y de la cordillera Central (Kussmaul, Gaínsa y Paniagua, 1982; Kussmaul, Tournon y Alvarado, 1994; Pérez, Alvarado y Gans, 2006).

\section{Comportamiento de la colada}

Una característica interesante de estas dos unidades de coladas, es que la unidad Ángeles Inferior se extiende de 2 a 2,5 km más que la unidad Ángeles Superior. Este comportamiento puede explicarse por la composición de las lavas, ya 

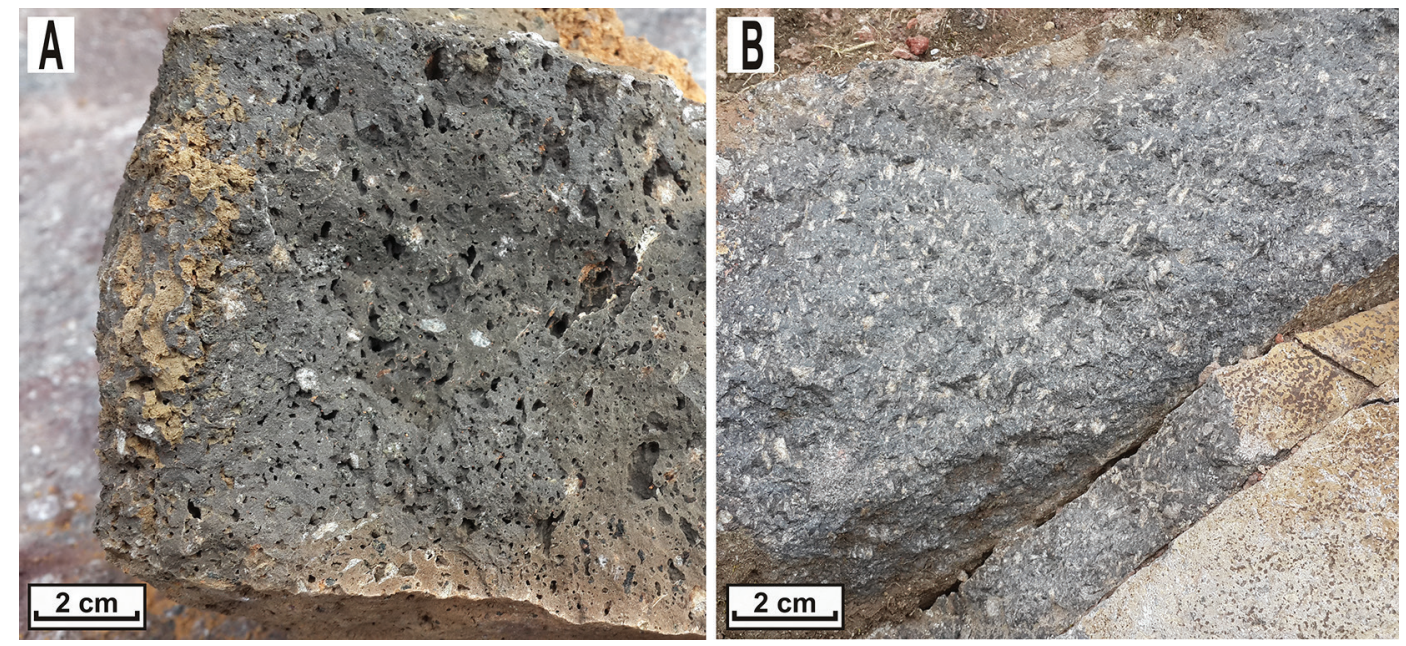

Fig. 8: Comparación textural macroscópica entre las unidades de la colada Ángeles. A) Unidad Ángeles Inferior: entre 10 - 15 \% de fenocristales, B) Unidad Ángeles Superior: comúnmente $25 \%$ y hasta $35 \%$ de fenocristales.

que este parámetro se relaciona directamente con la viscosidad del magma (Spera, 2002). La colada inferior es andesítico-basáltico, mientras la superior es andesítica, por lo tanto, es de esperar que tomando en cuenta únicamente ese factor, la colada inferior sea menos viscosa y por tanto pueda alcanzar mayores distancias, tal y como ocurre en este caso.

Otro factor a considerar según el cuadro 1 es la diferencia notable en el contenido de fenocristales, teniendo Ángeles Inferior entre 18 y $22 \%$ de fenocristales, ante 24 a $41 \%$ en Ángeles Superior.

Resulta conocido que a mayor contenido de fenocristales, aumenta la viscosidad. Sin embargo, la viscosidad y el contenido de fenocristales son dos variables difíciles de correlacionar mediante una ecuación sencilla debido a la complejidad reológica natural del magma. No obstante, la ecuación Einstein-Roscoe se ha considerado como válida asumiendo ciertas variables (Lejeune y Richet, 1995). La ecuación expresa:

$$
\text { Viscosidad }=V h\left(1-F / F_{\text {max }}\right)^{-2,5}
$$

En donde $V h$ es la viscosidad del fundido homogéneo, en este caso de tipo andesítico, por lo tanto el valor está $10^{5}$ y $10^{7}$ Poise de acuerdo con Lockwood y Hazlett (2010). Se usará un valor medio de $10^{6}$ Poise, considerando que una de ellas es andesítica y la otra es andesítico-basáltica. $F$ es la fracción de volumen de los cristales y $F_{\text {máx }}$ es la cristalinidad máxima, propuesta por Marsh (1981) con un valor de 0,6. Si aplicamos esta ecuación asumiendo un $20 \%$ de fenocristales, o sea una fracción de 0,2 para la colada inferior y $30 \%$, es decir 0,3 para la colada superior, se obtiene una viscosidad de $2,8 \times 10^{6}$ y $5,7 \times 10^{6}$ Poise respectivamente. De estos datos se desprende que la unidad Ángeles Superior posee una viscosidad relativa mayor que la Inferior, por tanto, se infiere que este parámetro pudo haber determinado, en parte, la diferencia de longitud entre las coladas, siendo la menos viscosa la más extensa.

\section{Morfocronología}

De los datos arqueológicos no se obtuvo ninguna información que permitiera ubicar la colada en un rango de tiempo confiable, ya que los 14 sitios documentados, tienen asignada una edad similar entre sí y no hay diferencias considerables entre las edades de los sitios dentro de la colada (1500 a. C. a 1550 d. C.) y fuera de ésta (1500 a. C. a 1350 d. C.). Con base en los datos arqueológicos tan solo se puede concluir que la edad mínima de la colada es de 3,5 ka. Por otro lado, geomorfológicamente, la colada presenta una 

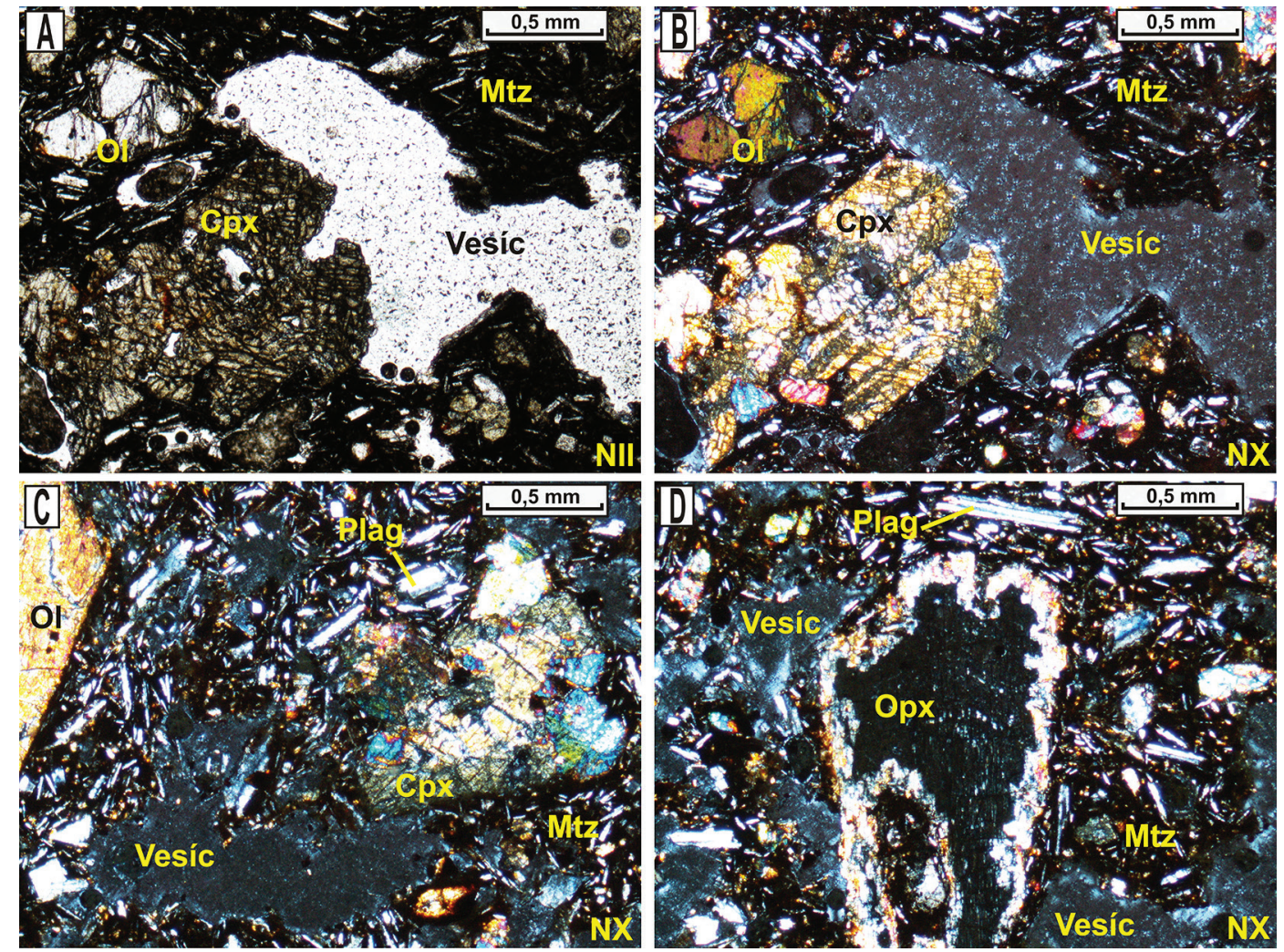

Fig. 9: Detalle microscópico de unidad Ángeles Inferior. A y B) Textura matriz: intersertal-vesicular, C) Textura general: hipocristalina porfirítica a levemente glomeroporfirítica, D) Megafenocristal de ortopiroxeno con textura en corona (rodeado de clinopiroxenos). NII: nícoles paralelos, NX: nícoles cruzados, Cpx: clinopiroxeno, Ol: olivino, Opx: ortopiroxeno, Plag: plagioclasa, Vesíc: vesícula y Mtz: matriz.

morfología marcada, poco meteorizada y erosionada y únicamente en los alrededores del cono es posible observar una cobertura de ceniza $(50 \mathrm{~cm}$ en promedio), en tanto que, en los demás sectores se encuentra sin ninguna cobertura y solamente ha desarrollado espesores de suelo cercanos a 1 $\mathrm{m}$. Por lo que se considera que podría tener una edad entre 4 y $15 \mathrm{ka}$, similar a la inferida por Arredondo y Soto (2006).

Estratigráficamente, al suroeste de Ángeles, la colada se observa sobreyaciendo de 1,5 a $2 \mathrm{~m}$ de un paleoaluvión con clastos desde los $0,5 \mathrm{~cm}$ a los 1,2 m de diámetro, el cual a su vez sobreyace a un paleosuelo. En el cauce del río Bermúdez, en Ángeles, también se observa sobreyaciendo a un paleosuelo. En los alrededores de San Rafael se encuentra sobre una colada de lava más antigua denominada en este trabajo como Paleo-Ángeles, de composición basáltica. Sobreyace a las coladas de lava antiguas de San Josecito, Turales y Puente de Salas, así como a algunos paquetes de tobas y cenizas (Soto, com. esc. 2014) y a los piroclastos de Porrosatí y Carbonal (Protti, 1986).

Las perforaciones del SENARA indican que sobreyace flujos de tobas e ignimbritas (BA843, BA166, BA683, BA451, BA734, BA451), cenizas (BA89) y paleoaluviones (BA529). La colada está sobreyacida por una delgada capa de ceniza y suelos húmicos (50 cm en promedio), que únicamente puede ser observada en las cercanías del cono del Monte de la Cruz y son posiblemente el resultado de la actividad del mismo.

Con respecto a los límites geográficos de la colada, los bordes este y oeste son claros desde el punto de vista geomorfológico y geológico, ya que el espesor de suelo a ambos lados de la 

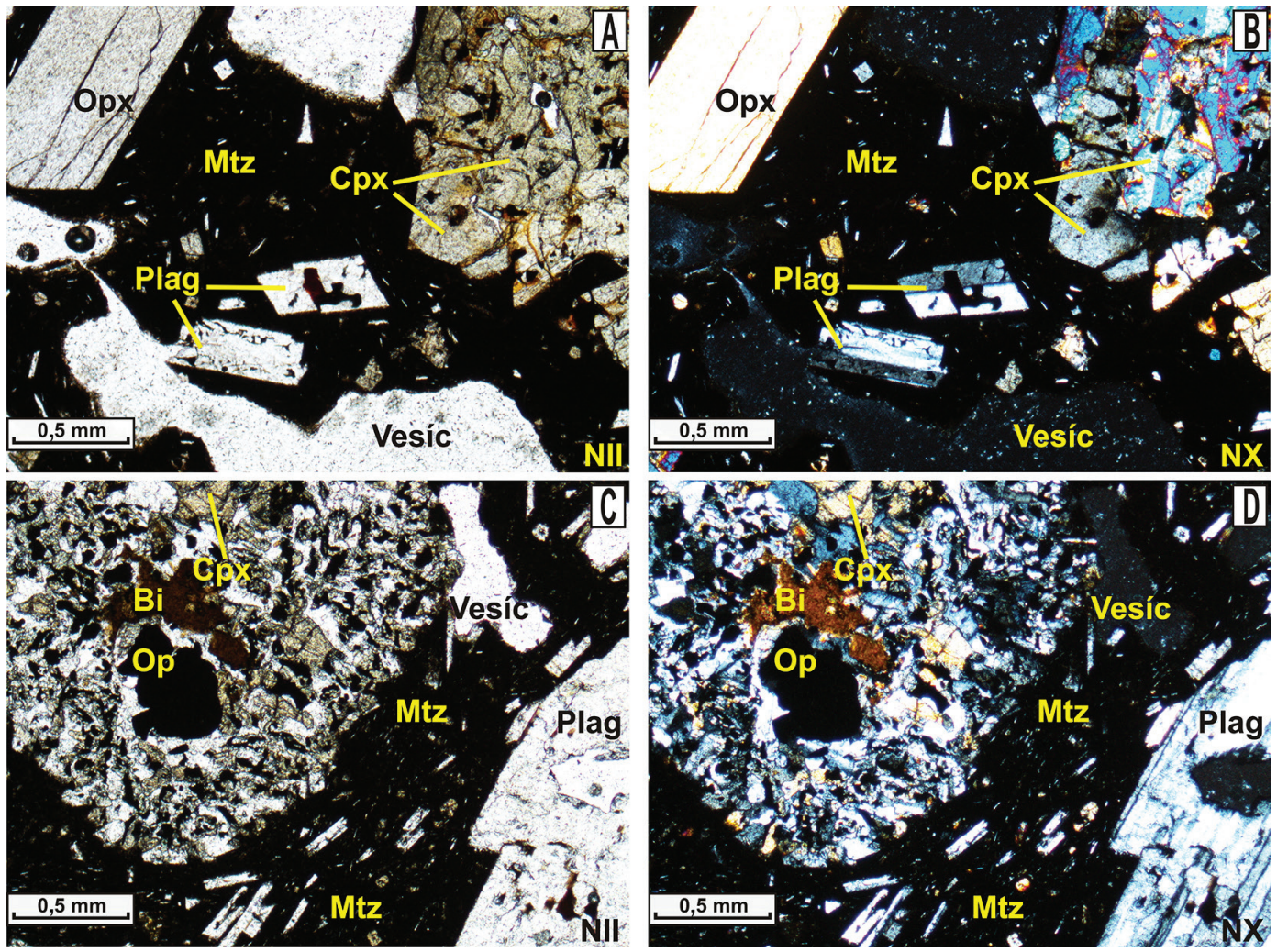

Fig. 10: Detalle microscópico de brecha de progresión o autobrecha, unidad Ángeles Superior. A y B) Matriz con fuerte alteración del vidrio a óxidos de hierro. C y D) Inclusión compuesta por plagioclasas, opacos, clinopiroxenos y biotita. NII: nícoles paralelos, NX: nícoles cruzados, Opx: ortopiroxeno, Cpx: clinopiroxeno, Plag: plagioclasa, Bi: biotita, Vesíc: vesícula y Mtz: matriz.

colada es mucho mayor $(>2,5 \mathrm{~m})$ que en el área de la colada. En cuanto al límite SW de la colada, la geomorfología muestra que se extiende hasta el centro de Barva, sin embargo, Protti (1968) propone que se extiende hacia San Joaquín de Flores. En una gira de comprobación realizada, no se observaron evidencias morfológicas de la continuación de la colada hacia San Joaquín, sin embargo, se observó una colada de lava que posee características macroscópicas similares a las de la unidad Ángeles Inferior pero que microscópicamente corresponde con una lava de composición basáltica, donde además los olivinos se presentan iddingsitizados y corroídos (485368 E / 1106775 N). Debido a estas diferencias petrográficas, la ausencia de una morfología marcada de la continuación del flujo hasta este punto y observando la información de algunos pozos del SENARA en esta área (BA475, BA272) que indican la existencia de otra serie de coladas, se infiere que la colada observada hacia Mercedes de Heredia sería una de estas coladas más antiguas que la colada Ángeles. Nuevos trabajos de geoquímica y dataciones serían necesarios para la comprobación de esta hipótesis.

Hasta el momento, la colada Ángeles se ha considerado de diversas formas, desde una sola colada de lava o un campo de lavas contemporáneo hasta un campo de lavas diacrónicas. Por ejemplo, se le considerada como un solo evento efusivo, o sea, una sola colada de lava (Williams, 1952; Dóndoli y Chaves, 1968; Echandi, 1981, Protti, 1986), o varias coladas en un intervalo de tiempo posiblemente muy corto (Schaufelberger, 1931, Soto com. esc. 2014), o incluso ha sido descrita como varias coladas intercaladas con depósitos de lahares y paleosuelos (Bohnenberger, 1968). El primer supuesto (una sola o un campo 


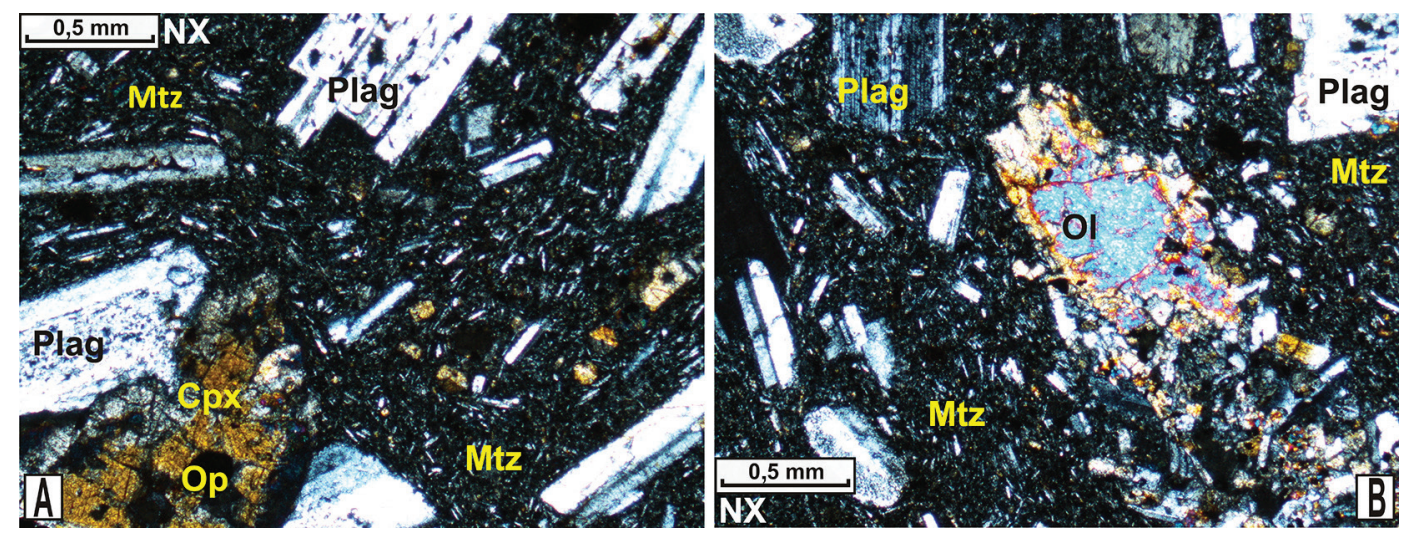

Fig. 11: Detalle microscópico de colada masiva, unidad Ángeles Superior. A) Textura general: hipocristalina glomeroporfirítica seriada. B) Olivino en inclusión. NII: nícoles paralelos, NX: nícoles cruzados, Ol: olivino, Opx: ortopiroxeno, Cpx: clinopiroxeno, Plag: plagioclasa, Vesíc: vesícula, Op: opaco y Mtz: matriz.

de coladas prácticamente isocrónicas) coincide con lo que se espera de un cono monogenético como ha sido postulado para el Monte de la Cruz. Sin embargo, las últimas dos premisas, descartarían que este cono sea monogenético y pasaría a considerarse como poligenético, donde la fisura que originó la colada Ángeles Inferior debe de estar cubierta por los depósitos del Monte de la Cruz y la colada Ángeles Superior. De acuerdo con nuestras observaciones de campo, se presentan dos coladas de lava separadas por un paleosuelo de poco espesor (máx. $15 \mathrm{~cm}$ ), sin rastros orgánicos evidentes, ambas con una morfología muy marcada y poco meteorizadas. No obstante, de la colada inferior solo puede observarse la parte distal y con base en su dirección de flujo y morfología fresca, se infiere un origen similar al del Monte de la Cruz. De esta forma, se concluye con seguridad que la colada Ángeles Superior se originó del Monte la Cruz, mientras que la Ángeles Inferior, al estar cubierta por la superior, no se sabe con certeza si sale de este mismo foco de emisión, o si sale de una zona cercana que forma parte del sistema fisural presente en el área. En tal caso, hoy día se conoce que algunos volcanes que se les consideró como monogenéticos, en realidad han tenido varias fases eruptivas distanciadas en el tiempo por décadas hasta incluso miles de años (ver McKnight y Williams, 1997; Alvarado et al., 2011). La colada de Cervantes es un caso, donde dos campos de lavas complejos (colada Oriental y colada Occidental), uno a la par del otro, son petroquímica y cronológicamente diferentes, originados de dos fisuras paralelas, pero la geomorfología no logra discernir un campo del otro (Alvarado y Vega, 2013). Más estudios (petrológicos, perforaciones y geocronológicos) son necesarios en lo que respecta a la colada Ángeles.

\section{MORFOMETRÍA DEL SISTEMA DE CONOS}

La ladera sur-sureste del volcán Barva se caracteriza por presentar tres zonas morfológicas bien diferenciadas (Fig. 12), la primera de ellas, ubicada al noroeste, es la más erosionada y está cortada por valles fluviales más profundos, con pendientes promedio de $15^{\circ}$. Hacia el sur, el cauce del río Ciruelas marca el límite entre la zona A y B (Fig. 12), siendo esta última la de topografía más suavizada con valles fluviales menos pronunciados y pendientes promedio de $8^{\circ}$, en esta zona es donde se encuentra la mayor densidad de conos parásitos, entre ellos el Monte de la Cruz. Estos conos poseen tamaños muy diferentes entre sí, sin embargo, tienen un diámetro que no supera los $900 \mathrm{~m}$. La zona $\mathrm{C}$ en cambio, corresponde con una zona montañosa de fuerte denudación asociada con los cerros Zurquí, de edad más antigua (0,57 y 0,40 Ma: Alvarado y Gans, 2012). 


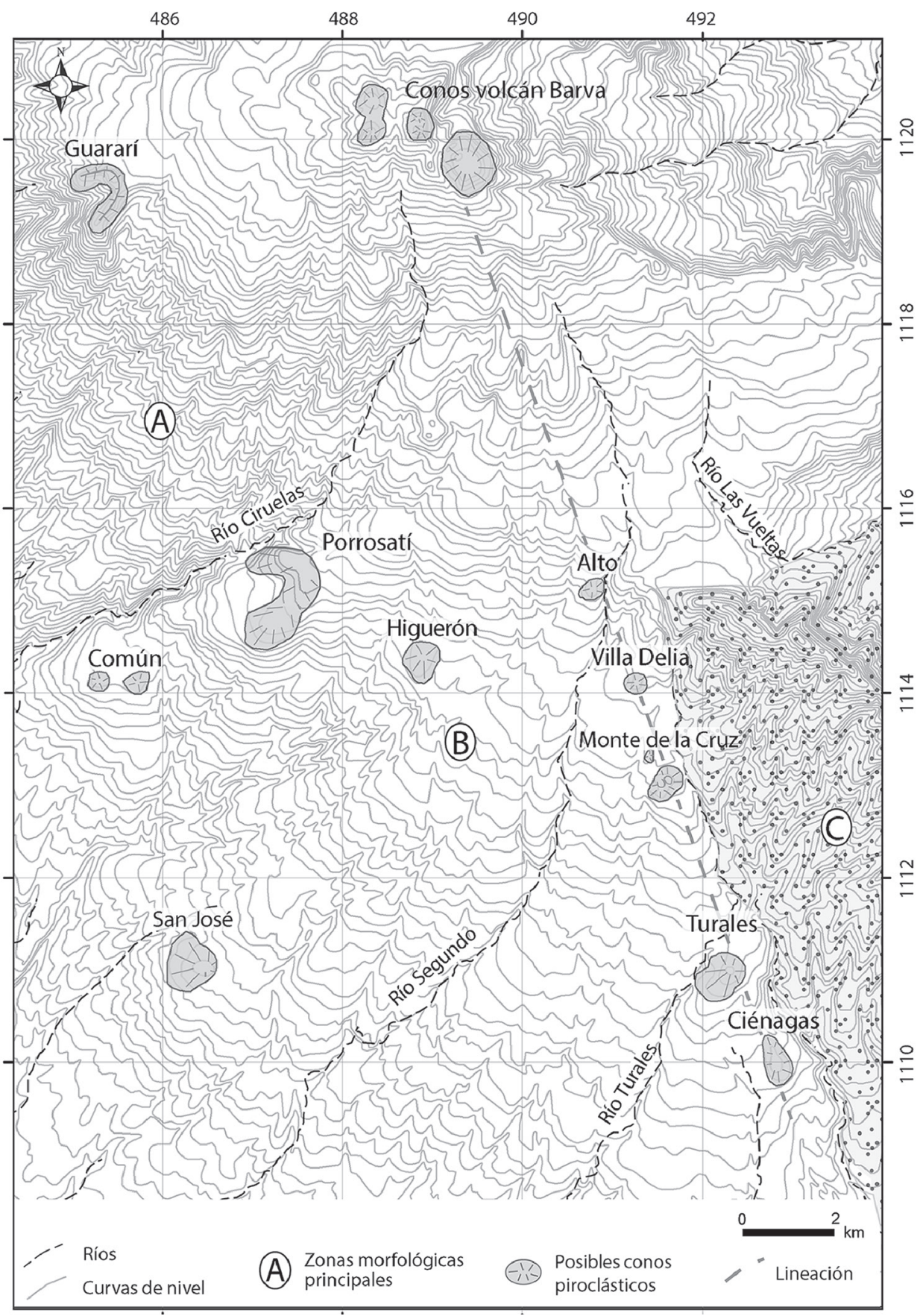

Fig. 12: Posibles conos piroclásticos del flanco sur del volcán Barva. La mayoría de los conos en la zona no tienen nombre, por lo que se les ha asignado un nombre tentativo para su mejor identificación. 
Algunos de los conos parásitos observados en el área de estudio son grandes, como el Porrosatí y San José (área: $0,23 \mathrm{~km}^{2}$ y $0,25 \mathrm{~km}^{2}$ respectivamente), mientras otros tienen un área mucho mejor como los cerros Común, Alto y Villa Delia (área: $0,05 \mathrm{~km}^{2}, 0,05 \mathrm{~km}^{2}, 0,04 \mathrm{~km}^{2}$, respectivamente). La mayoría de estos conos de escorias muestra su forma cónica bien conservada, varían entre 40 a $80 \mathrm{~m}$ de altura desde la base y tienen pendientes que rondan los $10^{\circ}$ en promedio, posiblemente por efectos de la erosión y meteorización.

A grandes rasgos, la posición de estos conos con respecto a la estructura del volcán es aleatoria, sin embargo, se observa una alineación $\mathrm{N} 19^{\circ} \mathrm{W}$ de $8,5 \mathrm{~km}$ de longitud entre los conos Ciénagas, Turales, Monte de la Cruz, Villa Delia, Alto y los cráteres principales del volcán Barva, indicando esto que dichos conos podrían haber sido originados por esta fractura volcano-tectónica. Por otro lado, los otros conos no se observan asociados a ningún lineamiento, por lo que podrían no ser contemporáneos a los anteriormente mencionados. No obstante, en este trabajo no fue posible comprobar o descartar esta hipótesis, por lo que sería interesante que en futuros trabajo de investigación se pueda establecer la cronología de evolución de estos conos de la falda sur del volcán Barva.

\section{CONCLUSIONES}

El cono del Monte de la Cruz presenta dos cráteres, uno de ellos con una laguna interna; posee además dos depresiones a los pies del cono, que se interpretan como dos posibles aperturas o cráteres cubiertos por piroclastos de caída producto de la actividad del cono.

Como resultado de la actividad volcánica del cono se identificaron dos unidades de flujo de la colada Ángeles, la unidad Ángeles Inferior y la unidad Ángeles Superior. La primera es la más extensa $(7,3 \mathrm{~km})$, llegando hasta el poblado de Barva de Heredia, en tanto que la unidad superior se extiende solamente $6,5 \mathrm{~km}$ y llega hasta el norte de San Rafael de Heredia. Por otra parte, se observó una colada con características macroscópicas similares a la unidad Ángeles Inferior hacia Mercedes del cantón de Heredia. Sin embargo, morfológicamente y petrográficamente no se observan evidencias claras de que sea el mismo flujo de Ángeles Inferior, por lo que se infiere que se trata de una colada subyacente. No obstante, se recomienda hacer análisis químicos y dataciones en futuras investigaciones para confirmar o descartar esta hipótesis.

Morfológicamente, en la colada superior se observaron varias depresiones, una de ellas relacionada con una kipuka, mientras que, las depresiones longitudinales fueron asociadas por sus características morfológicas con levées, uno de los cuales, ubicado en Getsemaní, posee hasta $500 \mathrm{~m}$ de longitud y $100 \mathrm{~m}$ de ancho. En la colada inferior se observó solamente un levée y se definieron diferentes direcciones de flujo a lo largo de las dos coladas, todas ellas con dirección SE. Así mismo, un tubo de lava de pequeñas dimensiones fue observado cerca de Ángeles.

Se determinaron los espesores promedio de la colada superior e inferior (30 $\mathrm{m}$ y $15 \mathrm{~m}$ respectivamente), tanto por medio de trabajo de campo como por medio de la revisión de pozos del SENARA, mientras el área y volumen de la colada de lava fueron calculados en $12,8 \mathrm{~km}^{2}$ y de 0,2 $\mathrm{km}^{3}$ a $0,3 \mathrm{~km}^{3}$, respectivamente.

Desde el punto de vista litológico y petrográfico, la unidad Ángeles Inferior es brechosa y está conformada por bloques escoriáceos de tipo andesítico basáltico, con poco desarrollo de un paleosuelo en la parte superior (espesor máximo $15 \mathrm{~cm}$ ). Sobre esta se encuentra la unidad Ángeles Superior, conformada por varias coladas masivas alternadas entre sí por sus brechas de progresión y cuya composición es andesítica. Macroscópicamente, ambas unidades se diferencian entre sí por el porcentaje de fenocristales, ya que la unidad Ángeles Inferior presenta entre $10-15 \%$, mientras la unidad Ángeles Superior posee entre 25-30\%. Microscópicamente, la unidad Ángeles Inferior corresponde con lavas de composición andesítico 
basáltico con textura hipocristalina, porfirítica a levemente glomeroporfirítica con fenocristales de plagioclasa, clinopiroxenos, ortopiroxenos, olivino y opacos en una matriz intersertal-vesicular; mientras la unidad Ángeles Superior son lavas andesíticas con textura hipocristalina, glomeroporfirítica a glomeroporfirítica seriada, con fenocristales de plagioclasa, clinopiroxenos, ortopiroxenos, olivinos y opacos, en una matriz intersertal-vesicular y menos común pilotaxítica.

Utilizando la ecuación de Einstein-Roscoe se comparó la viscosidad de ambas unidades, dando como resultado $2,8 \times 10^{6}$ Poise para la Inferior y $5,7 \times 10^{6}$ Poise para la Superior, permitiéndonos inferir que, tal y como se supondría, el grado de viscosidad está relacionado con la distancia recorrida por el flujo de lava de Ángeles, su composición petrográfica y porcentaje modal de fenocristales. En este caso, la colada andesítico-basáltica sería la más extensa y menos viscosa (unidad Ángeles Inferior: 7,3 km), mientras la colada andesítica sería la menos extensa y más viscosa en comparación (unidad Ángeles Superior: 6,5 km).

A pesar que no se realizaron dataciones, se reafirma que esta colada es posiblemente la más joven del volcán Barva (coincidiendo con lo que indican otros autores). Por tanto, se favorece la estimación de la edad entre 4 y 15 ka similar a la propuesta por Arredondo y Soto (2006).

Regionalmente, se observaron una serie de posibles conos de escoria asociados al volcán Barva, que deben estudiarse para determinar su origen, los cuales en su mayoría están distribuidos aleatoriamente. Sin embargo, los ubicados en el sector este, entre ellos el Monte de la Cruz, están alineados con dirección $\mathrm{N} 19^{\circ} \mathrm{W}$, por lo que se interpreta que la actividad volcánica de estos conos está asociada a una actividad fisural con esta orientación.

Si se toma la hipótesis de que la colada Ángeles Inferior proviene del Monte de la Cruz, al estar separada de Ángeles Superior por un paleosuelo, sugeriría que este cono es de tipo poligenético y no monogenético como suele atribuirse a los conos de escorias.

\section{AGRADECIMIENTOS}

Este trabajo formó parte del proyecto de investigación denominado "Geología y petrografía de la colada Los Ángeles, flanco SE del volcán Barva", número 814-B3-769, del Centro de Investigaciones en Ciencias Geológicas (CICG) de la Universidad de Costa Rica. Se agradece el apoyo brindado por este centro y la Escuela Centroamericana de Geología.

También agradecemos a la Comisión Nacional de Emergencias (CNE) que nos facilitó una gira de campo. A Irene Aguilar y Johan Sandoval por su colaboración durante una de las giras de campo. A Blas Sánchez por el aporte de algunas fotografías y a Gerardo Soto por las descripciones suministradas. A la administración del tajo La Florida por permitirnos el ingreso y toma de muestras representativas. A la M.Sc. Myrna Rojas, jefe del Departamento de Antropología e Historia del Museo Nacional, por los datos de las edades de los sitios arqueológicos. Un agradecimiento especial a Mainor Arce del Centro Turístico Paradero Monte de la Cruz por su colaboración y guía. Se agradece también a Oscar Chavarría Sánchez por guiarnos al tubo de lava y a Antigüedades Getsemaní.

\section{REFERENCIAS BIBLIOGRÁFICAS}

Arredondo, S. y Soto, G. (2006). Edad de las lavas del Miembro Los Bambinos y sumario cronoestratigráfico de la Formación Barva, Costa Rica. Revista Geológica de América Central, 34-35, 59-71.

Alvarado, G. E. Soto, G. Salani, F. Ruiz, P. y Hurtado, L. (2001). The formation and evolution of Hule and Río Cuarto maars, Costa Rica. Journal of Volcanology and Geothermal Research, 201, 342-356.

Alvarado, G. E. y Vega, A. E. (2013). La geomorfología de la colada de Cervantes, volcán Irazú (Costa Rica): descripción de 
uno de los campos de lava más grandes de América Central. Revista Geológica de América Central, 48: 99-118.

Bohnenberger, O. (1968). A photogeological study of western central valley, Costa Rica. San José: Naciones Unidas.

Dóndoli, C. (1965). Volcanismo Reciente de Costa Rica. Dirección de Geología, Minas y Petróleo, Informe Técnico y Notas Geológicas, 4, 15-b.

Dóndoli, C. y Chaves, R. (1968). Mapa adjunto al estudio geológico del Valle Central (escala 1: 150 000). San José: IGN.

Echandi, E. (1981). Unidades volcánicas de la vertiente norte de la cuenca del río Virilla (Tesis de licenciatura inédita). Universidad de Costa Rica, San José, Costa Rica.

Kussmaul, S. Gaínsa, J. y Paniagua, S. (1982). Recopilación, clasificación e interpretación petroquímica de las rocas de Costa Rica. Informe Semestral, 17-79.

Kussmaul, S. Tournon, J. y Alvarado, G. E. (1994). Evolution of the Neogene to quaternary igneous rocks of Costa Rica. Profil, 7, 97-123.

Lejeune, A. y Richet, P. (1995). Rheology of crystal-bearing silicate melts: an experimental study at high viscosities. Journal of Geophysical Research, 100, 4215-4229.

Lockwood, J. y Hazlett, R. (2010). Volcanoes: global perspectives. Oxford, U. K.: Wiley y Blackwell.

Marsh, B. (1981). On the crystallinity, probability of occurrence, and rheology of lava and magma. Contributions to Mineralogy and Petrology, 78, 85-98.

McBirney, A. y Williams, H. (1965). Volcanic history of Nicaragua. University of California Publications in Geological Sciences, 55, 1-65

McKnight, S. B. y Williams, S. (1997). Old cinder cone or young composite volcano?: the nature of Cerro Negro, Nicaragua. Geology, 25(4), 339-342.

Pérez, W. Alvarado, G. E. y Gans, P. (2006). The Tiribí tuff: stratigraphy, geochronology and mechanism of deposition of the largest and most recent ignimbrite in the Valle Central, Costa Rica. Bulletin of Volcanology, 69, 25-40.

Protti, R. (1986). Geología del flanco sur del volcán Barva, Heredia, Costa Rica. Boletín de Vulcanología, 17, 23-31.

Sáenz, R. (1971). Aparatos volcánicos y fuentes termales de Costa Rica. Dirección de Geología, Minas y Petróleo, Informe Técnico y Notas Geológicas, 41, 1-16.

Salguero, M. (2007). Caminos y veredas de Costa Rica. San José: EUNED.

Schaufelberger, P. (1931). Cráteres parásitos del macizo volcánico. Apuntes de Geología, 3, 1-11.

Spera, F. (2000). Physical properties of magma. En: H. Sigurdsson (ed.), Encyclopedia of volcanoes (pp. 171-190). Academic Press, New York.

Williams, H. (1952). Volcanic history of the meseta central occidental Costa Rica. University of California Publications in Geological Sciences, 29(4), 145-180. 
